\title{
The 400-Meter Walk Test to Evaluate Walking Performance between Diabetics and Healthy Females
}

\author{
Ronald Pakasi $^{1}$, Angela BM Tulaar ${ }^{2}$, Sarwono Waspadji ${ }^{3},(\dagger)$ Corrie Wawolumaya $^{4}$ \\ ${ }^{1}$ Department of Medical Rehabilitation, Fatmawati General Hospital, Jakarta \\ ${ }^{2}$ Department of Physical Medicine and Rehabilitation, Faculty of Medicine - University of Indonesia, Jakarta \\ ${ }^{3}$ Department of Internal Medicine, Faculty of Medicine - University of Indonesia, Jakarta \\ ${ }^{4}$ Department of Community Medicine, Faculty of Medicine - University of Indonesia, Jakarta
}

\begin{abstract}
Objective: to evaluate walking performance in female with type 2 diabetes mellitus (DM2) with the 400-meters walk test (400-MWT) compared to healthy individuals.

Methods: two groups of female subjects with DM2 and healthy individuals were matched by the age. The 400-MWT parameters to be compared were walking speed (WS) and predicted maximum oxygen consumption (pVO2max). Baseline examination included body mass index (BMI), random blood glucose (RBG), and ankle-brachial index (ABI). All subjects performed 2 minutes warm up before the test. Heart rate (HR) was recorded every 30 seconds, and blood pressure (BP) was measured before warm up and within 60 seconds after test. The test was performed twice on a different day.

Results: Nineteen subjects on each group participated in the study. The mean WS was significantly different $(\mathrm{p}<0.0001)$ between the study group $(1.26 \pm 0.19$ and $1.31 \pm 0.17 \mathrm{~m} / \mathrm{s})$ and the control group $(1.70 \pm 0.20$ and $1.78 \pm 0.24 \mathrm{~m} / \mathrm{s})$ for the first and second tests respectively. There was a significant difference of mean $\mathrm{pVO} 2 \max (\mathrm{p}<0.0001)$ between the study group $(17.22 \pm 2.94$ and $17.99 \pm 2.36 \mathrm{ml} /$ $\mathrm{kg} / \mathrm{min})$ and the control group $(23.68 \pm 3.79$ and $24.44 \pm 3.74 \mathrm{ml} / \mathrm{kg} / \mathrm{min})$.
\end{abstract}

Conclusion: the 400-MWT demonstrated lower walking performance in female subjects with DM2 compared to healthy individuals.

Keywords: Type $2 \mathrm{DM}$, healthy individuals, 400 meter walk test, walking speed, $\mathrm{VO}_{2 \max }$.

\section{INTRODUCTION}

Walking performance is a representation of cardiopulmonary capacity and fitness level of an individual with type 2 DM (DM2). In women with DM2 a decrease in cardiopulmonary capacity may be related to increased C-reactive protein (CRP) level and reduced fasting blood

Received in March 2013 and accepted for published in April 2013.

Correspondence address: SMF Rehabilitasi Medik, Ged. Prof. Soelarto 1t.4, RSUP Fatmawati, Jl. RS Fatmawati, Cilandak, Jakarta Selatan 12430. Email: ronaldpakasi@gmail.com glucose control. ${ }^{1}$ Reduced cardiopulmonary capacity and fitness level may lead to further macrovascular and microvascular complications of DM $2 .^{2}$

The standard test to evaluate walking performance is treadmill exercise test. ${ }^{3}$ However treadmill test has a technical disadvantages that it must be performed in certain institution that provide such facility. With the increasing needs to evaluate fitness level in DM2 patients, an exercise test that provide technical flexibility and easy to perform become a major issue.

The corridor walk test has been an alternative methods to evaluate cardiopulmonary performance. The most common corridor walk 
tests used widely were the 6 minutes and the 12 minutes walk tests. Long distance corridor walk test is a relatively new methods to evaluate walking performance. The 400 meter walk test (400 MWT) is an example of distance-targeted exercise test. ${ }^{4}$

The 400 MWT was initially developed by Simonsick et al. $^{4}$ to evaluate walking performance in geriatric patients. In several studies, inability to walk 400 meters in 15 minutes has been defined as disability in mobility. ${ }^{4-6}$ In a comparative study by Simonsick et $a 1,{ }^{7}$ the 400 MWT demonstrated better achievements compared to the 6 minutes walk test. In this study, subjects accomplished higher walking speed when given targeted distance compared to targeted time.

In women with DM2, the 400 meters distance has been used as a threshold value to determine walking disability. 5,8 However, evaluation of walking performance in women with DM2 using the 400 MWT has not been used earlier. The objective of this study is to evaluate walking performance in women with DM2 using the 400 MWT compared with healthy female individuals. The parameters used in this study includes walking speed (WS) and predicted maximum oxygen consumption (pVO2max).

\section{METHODS}

\section{Design}

The design is a comparative cross-sectional study between 2 paired groups.

\section{Subjects}

The subjects in this study were enrolled from Medical Rehabilitation Polyclinic and Metabolic-Endocrine Polyclinic in Cipto Mangunkusumo Hospital, Jakarta. The time of this study was between July - September 2007. All subjects were female matched by the age group, and divided into the study and control groups.

The inclusion criteria of the study group subjects include: had type $2 \mathrm{DM}$ without a complication of peripheral arterial disease, able to walk without using any assistive device, and controlled blood glucose level with appropriate medications. For the control groups the inclusion criteria were healthy individuals, no history of DM2 or other hyperglycemia-related metabolic syndrome, able to walk without assistive device, normal $\mathrm{RBG}$, resting $\mathrm{BP}$, and ABI values.

The exclusion criteria include: indication of peripheral arterial disease with ABI score $<0.9, \mathrm{RBG} \geq 300 \mathrm{mg} / \mathrm{dl}$ or $\leq 80 \mathrm{mg} / \mathrm{dl}$, resting HR $>120 \mathrm{x} /$ minutes, history of stroke or any other conditions that may cause paresis of the lower extremity, history of diabetic foot ulcer, recent heart disease within 6 month prior to the test, uncontrolled hypertension, and complication of diabetic retinopathy and/or nephropathy.

Subjects will be classified as drop out if hypoglycemia presents during the test and/or unable to finish all of the test sessions.

\section{Informed Consent and Ethical Clearance}

All subjects was given oral and written explanation about the procedure. Subjects that agreed to participate in the study were asked to signed written Informed Consent form before the study.

This study has passed an ethical clearance issued by the Ethical Committee for Research from the Faculty of Medicine, University of Indonesia.

Materials used in this study includes: sphygmomanometer (Riester-Nova TM), stethoscope (Littmann ${ }^{\mathrm{TM}}$ ), hand-held Doppler Ultrasound (Minidop FS-100VX) with $5 \mathrm{MHz}$ probe, road cones and an indoor 20-meters tract, glucometer (Super Glucocard II GT-1640 series), pedometer (JS-208 model), measuring tape, weight and height scales, stopwatch (Casio TM), pulse Monitor (Opto-Electronics PU-711 model), portable oxygen tank with masks (for emergency), and sweets or candies (if hypoglycemia presents).

All subjects that agreed to participate this study had been given written explanation and signed an informed consent form. Subjects were matched by the age group, and divided into two groups: the study and control groups. All subjects undergone thorough medical history taking, physical examination, blood glucose levels, and ankle-brachial index measurement using hand held Doppler. The body mass index 
was calculated to further ensure homogeneity between subjects.

The 400 MWT was taken twice on two random days to minimize learning effect. Each test session was taken exclusively for 1 subject to reduced the possibility of a bias. The 400 MWT protocol used in this study was based on the design by Simonsick et.al. ${ }^{4,7}$

Prior to the test the RBG, resting BP and HR were measured. All subjects were ask to perform 2 minutes of warm up in a 20-m tract. Each end of the tract was marked by a road cone, and subjects were asked to go about each of the road cones forming a continuous path. Subjects were asked to maintain an even walking speed and covered the ground as much as possible. Standardized encouragement was given on each turn and subjects were given signs before the warm up time stopped. Heart rate was recorded every 30 seconds from the beginning, and blood pressure was recorded before and immediately after warm up.

The exercise test was performed within 60 seconds after warm up. All subjects were to walk as fast as possible, covering 400 meters distance in 10 rounds. Standard encouragements were given on every round. The heart rate and blood pressure were recorded as in the warm up. Two parameters were calculated in this study, the WS and $\mathrm{pVO} 2 \mathrm{max}$.

Calculation of Predicted Maximum Oxygen Consumption

The pVO2max formula used in this study was developed by Simonsick et al.: ${ }^{7}$

$$
\mathrm{pVO}_{2 \max }=39.431-\left(0.054 \times \mathrm{t}_{400 \mathrm{~m}}\right)+(2.832 \times \mathrm{LS})-(0.031 \times \mathrm{SBP} \mathrm{60})-(0.064 \times \mathrm{CF})
$$

with

- $\quad$ VVO2max $=$ predicted maximum oxygen consumption ( $\mathrm{ml} / \mathrm{kg} / \mathrm{min})$

- $\mathrm{t}_{400 \mathrm{~m}}=$ elapsed time after $400-\mathrm{m}$ walk completed (seconds).

- $\quad$ LS $=$ longstride score: if the stride length $<1.2$ steps/meter

(total steps $<24$ steps $/ 20$ meter) the score $=1$, other than that $=0$.
- $\mathrm{CF}=$ correction factor: if the $\mathrm{t}_{400 \mathrm{~m}} \geq 240$ seconds, the score $=0$.

If the $\mathrm{t}_{400 \mathrm{~m}}<240$ seconds, then:

$C F=\mathrm{t}_{400 \mathrm{~m}}$ (seconds) -240 (seconds) $X(-$ $0.064)$.

The $(-0.064)$ value is the estimation parameter.

- $\mathrm{SBP}_{60}=$ systolic blood pressure taken within 60 seconds after the 400-meter laps completed.

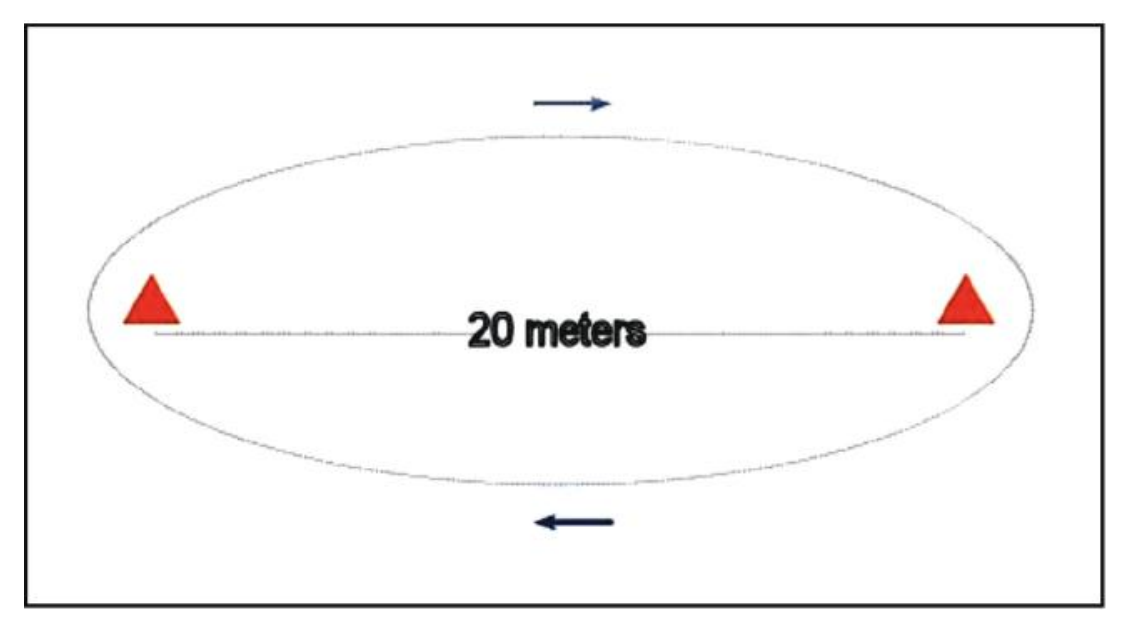

Picture 1. 20-meters Tract 

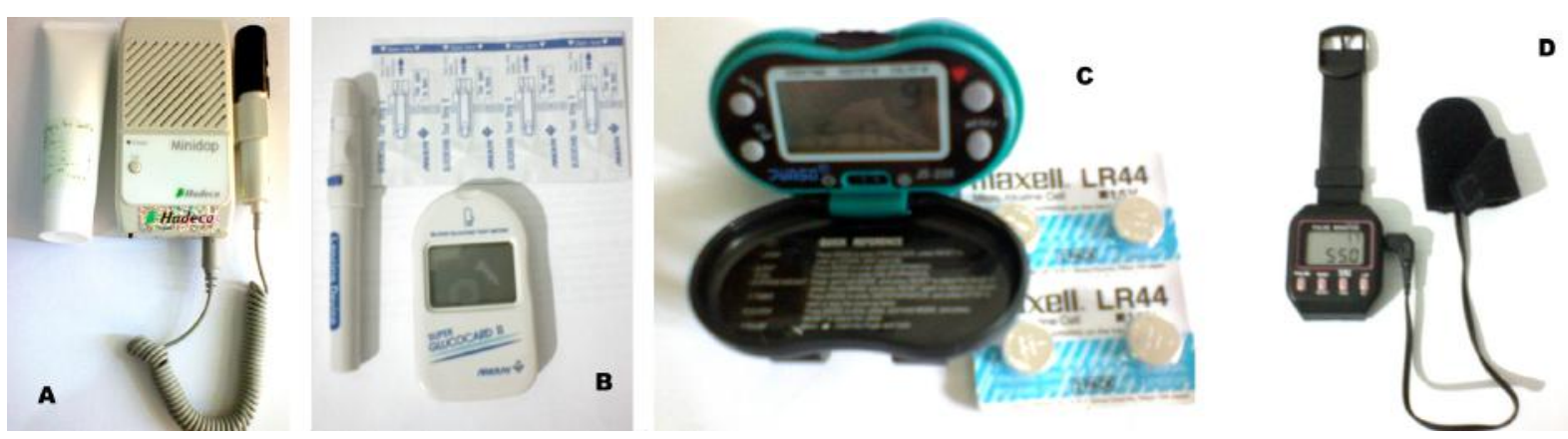

Picture 2. (A) Doppler Minidop-FS-100VX. (B) Glucometer (Super Glucocard II, GT-1640). (C). Pedometer JS-208. (D). Pulse Monitor Opto-Electronics PU-711
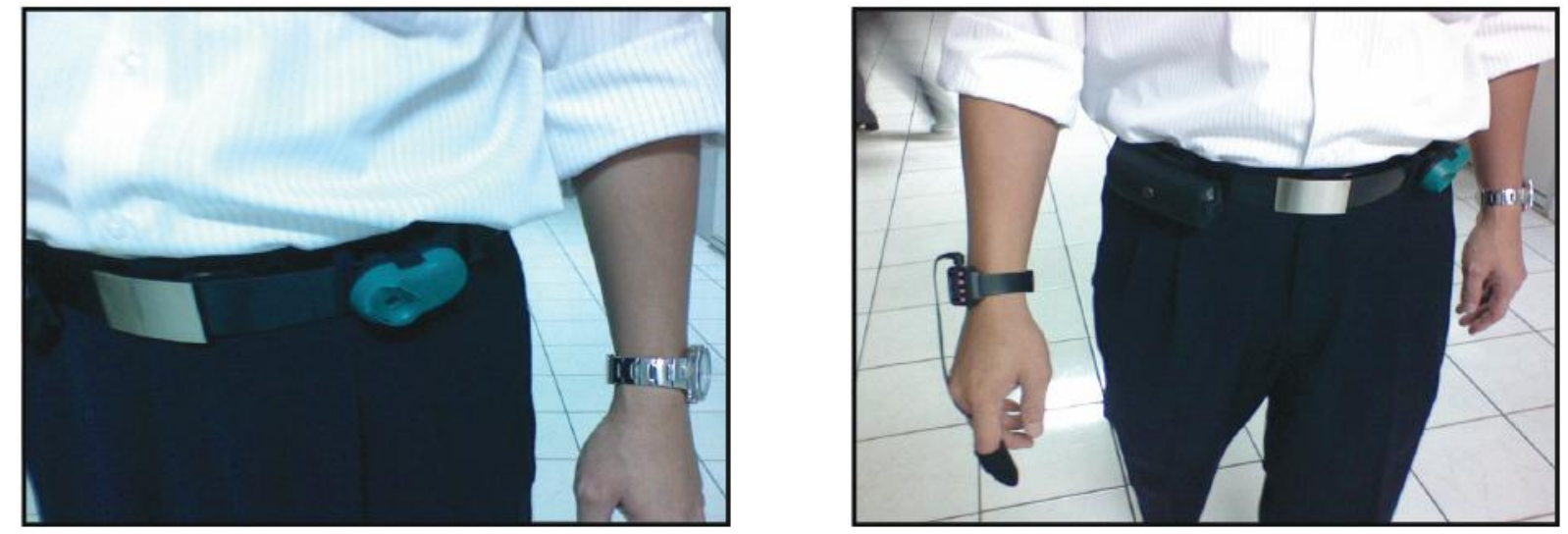

Picture 3. Pedometer and Pulse Monitor Application

\section{Statistical Analyses}

Statistical analysis was performed using SPSS v. 13.0 software. Data analysis was categorized into

1. Descriptive Study:

- Numerical variables: age, $\mathrm{SBP}_{60}$, $\mathrm{t}_{400 \mathrm{~m}}$, longstride, WS, and $\mathrm{pVO} 2 \mathrm{max}$, presented in mean value (Standard Deviation).

- Categorical variable was age group, presented in precentage (\%).

2. Analytic Study: paired t-test will be used if data distribution was normal, or the Wilconxon analysis if the data distribution non-normal.

\section{RESULTS}

From July to September 2007, there were 38 subjects participated in the study, nineteen on each group. For the study group, subjects were taken from Medical Rehabilitation Poylclinic and Metabolic-Endocrine Polyclinic. All subjects were patients with DM2. For the control group, all subjects were healthy volunteer who agreed to participate in the study.

\section{Subject Characteristics}

All subjects were divided into 3 age groups: 4049, 50-59, and 60-69 years old. Age range in the study group was 43-68 years of age (mean 54.5 \pm 7.752 , and for the control group 41-68 years of age (mean $54 \pm 8.266$ ). Subject distribution between the two groups was normal.

Table 1 shows general characteristics of all subjects. The majority of subjects in the study group were housewives $(52.6 \%)$, while the occupation in the control group were governor employee (68.4\%). Average level of education was college level on both groups. 
Table 1. Subject Distribution Based on Age, Occupation, and Education Level Between the Study and Control Groups

\begin{tabular}{|c|c|c|c|c|}
\hline \multirow{2}{*}{ Parameters } & \multicolumn{2}{|c|}{ Study $(N=19)$} & \multicolumn{2}{|c|}{ Control $(n=19)$} \\
\hline & $\mathbf{n}$ & $\%$ & $\mathbf{n}$ & $\%$ \\
\hline \multicolumn{5}{|l|}{$\begin{array}{l}\text { Age Classification } \\
\text { (years) }\end{array}$} \\
\hline $40-49$ & 7 & 36.8 & 7 & 36.8 \\
\hline $50-59$ & 7 & 36.8 & 7 & 36.8 \\
\hline $60-69$ & 5 & 26.4 & 5 & 26.5 \\
\hline \multicolumn{5}{|l|}{ Occupation } \\
\hline Governor employee & 4 & 21.1 & 13 & 68.4 \\
\hline Private employee & 1 & 5.3 & 0 & 0 \\
\hline Housewive & 10 & 52.6 & 0 & 0 \\
\hline Retired & 4 & 21.1 & 5 & 26.3 \\
\hline Others & 0 & 0 & 1 & 5.3 \\
\hline \multicolumn{5}{|l|}{ Education Level } \\
\hline College / university & 7 & 36.8 & 9 & 47.4 \\
\hline High school & 6 & 31.6 & 8 & 42.1 \\
\hline Elementary school & 6 & 31.6 & 2 & 10.5 \\
\hline
\end{tabular}

From 19 subjects in the study group, 14 patients had an onset of DM2 less than 10 years $(73.7 \%)$, while 5 patients had DM2 for 11 years or more (26.3\%). Most common comorbidities in the study group was hypertension and dyslipidemia ( $\mathrm{n}=12,63.2 \%$ on both comorbidities) and in the control group was dyslipidemia $(\mathrm{n}=$ $6,31.6 \%)$. All of the subjects had received proper medications for their conditions. Other comorbidities on both groups was knee osteoarthritis and past history of cardiovascular events. However, none of the subjects on both groups had recent cardiovascular diasese within the past 6 months. Signs of neuropathy such as paresthesia and numbness were found in 10 subjects of study group (52.6\%) and in 5 subjects in the control group (26.3\%). However all subjects had normal gait pattern without history of walking difficulty.

Ankle brachial index on both groups were normal. In the study group ABI was $1.08 \pm$ 0.161 , and in the control group $1.09 \pm 0.134$. No significant difference in $\mathrm{ABI}$ value between the
2 groups $(\mathrm{p}=0.717)$.

Mean BMI on the study group was $27.58 \pm$ $5.78 \mathrm{~kg} / \mathrm{m}^{2}$ with normal distribution $(\mathrm{p}=0.200)$. In the control group mean BMI was $24.61 \pm$ $3.38 \mathrm{~kg} / \mathrm{m}^{2}$ also showing normal distribution ( $\mathrm{p}$ $=0.200)$. The difference in BMI values among the 2 groups was not significant $(\mathrm{p}=0.063)$.

\section{Walking Speed}

Mean WS in the study group was $1.28 \pm 0.17$ $\mathrm{m} / \mathrm{s}(\mathrm{p}=0.085)$, while in the control group $1.74 \pm 0.21 \mathrm{~m} / \mathrm{s}(\mathrm{p}=0.200)$. Walking speed distribution on both groups was normal.

Table 2 displayed a comparison of WS from the first and second tests on both groups. There is no significant difference in mean WS between the first and second tests in the study group $(\mathrm{p}=0.121)$. In the control group, mean WS between the first and second tests showed a significant difference $(p=0.037)$. However the difference was not significant when compared within the age groups. 
Table 2. Mean Walking Speed from the First and Second Tests in Study and Control Groups

\begin{tabular}{|c|c|c|c|c|c|c|}
\hline \multirow{2}{*}{$\begin{array}{c}\text { Age Clasification } \\
\text { (years) }\end{array}$} & \multicolumn{3}{|c|}{ Study $(N=19)$} & \multicolumn{3}{|c|}{ Control $(n=19)$} \\
\hline & Mean (m/s) & SD & $\mathbf{p}^{+}$ & Mean $(m / s)$ & SD & $\mathbf{p}^{+}$ \\
\hline \multicolumn{7}{|l|}{ Mean } \\
\hline Test 1 & 1.26 & 0.19 & & 1.70 & 0.20 & \\
\hline Test 2 & 1.31 & 0.17 & 0.121 & 1.78 & 0.24 & $0.037^{*}$ \\
\hline \multicolumn{7}{|l|}{$40-49$} \\
\hline Test 1 & 1.33 & 0.16 & & 1.77 & 0.13 & \\
\hline Test 2 & 1.37 & 0.11 & 0.567 & 1.88 & 0.19 & 0.175 \\
\hline \multicolumn{7}{|l|}{$50-59$} \\
\hline Test 1 & 1.27 & 0.17 & & 1.73 & 0.21 & \\
\hline Test 2 & 1.35 & 0.20 & 0.222 & 1.86 & 0.21 & 0.054 \\
\hline \multicolumn{7}{|l|}{$60-69$} \\
\hline Test 1 & 1.14 & 0.218 & & 1.55 & 0.23 & \\
\hline Test 2 & 1.17 & 0.15 & 0.476 & 1.53 & 0.18 & 0.456 \\
\hline
\end{tabular}

Mean WS difference between the study and control groups are shown in Picture 4 . There was a significant difference on mean
WS between the study and control groups ( $p$ $<0.0001$. The result was consistent within age group comparison (Table 3 ).

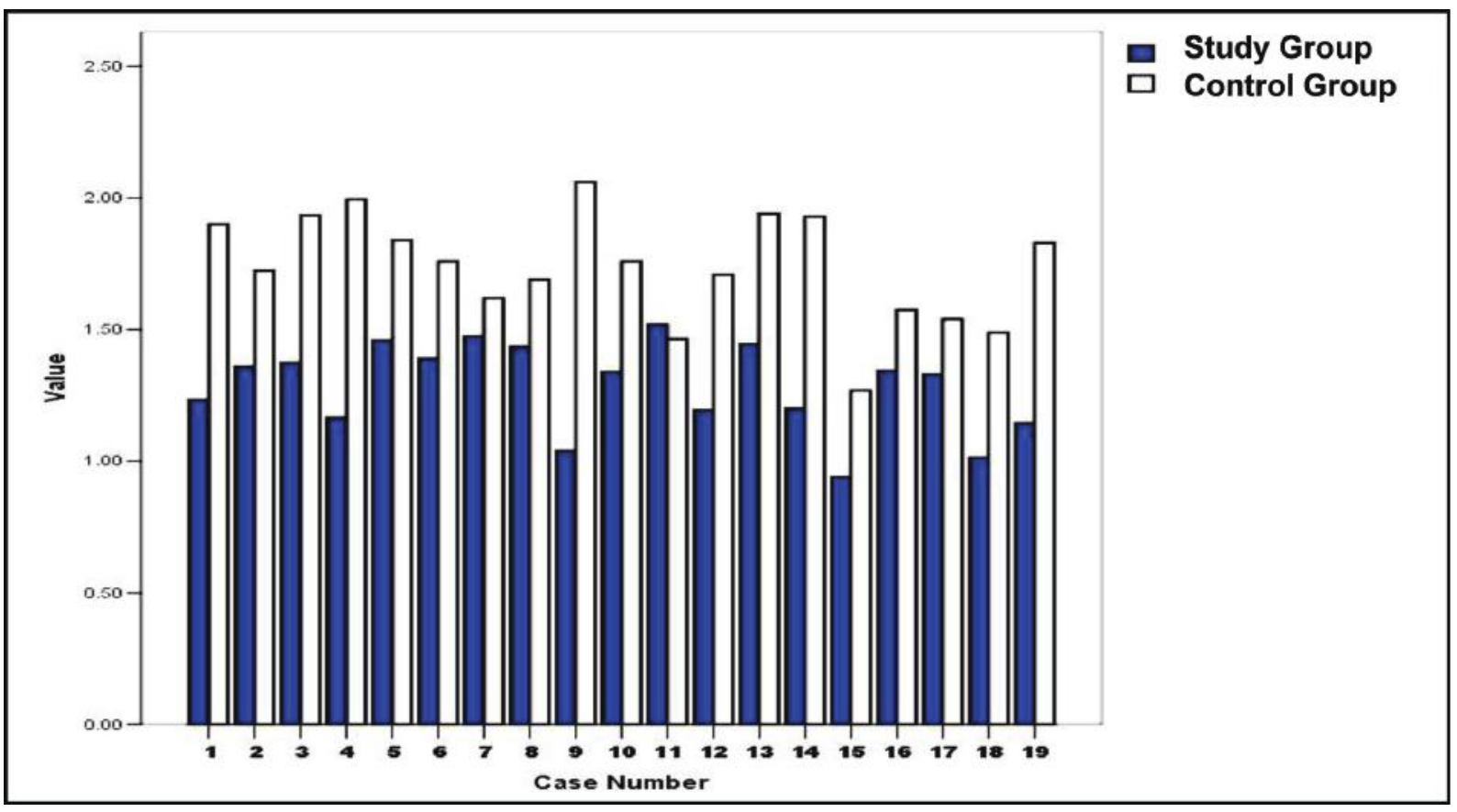

Picture 4. Comparison of Mean Walking Speed in Study and Control Groups 
Table 3. Mean Walking Speed Comparison Between Study and Control Groups Based on the Age Classification

\begin{tabular}{cccccc}
\hline \multirow{2}{*}{$\begin{array}{c}\text { Age Classification } \\
\text { (Year) }\end{array}$} & $\boldsymbol{\Delta}$ & \multicolumn{5}{c}{ Paired Differences } \\
\cline { 2 - 6 } & -0.453 & SD & $\mathbf{t}$ & $\mathbf{d f}$ & $\mathbf{p}^{*+}$ \\
\hline General & -0.474 & 0.258 & -7.684 & 18 & $<0.0001$ \\
$40-49$ & -0.483 & 0.341 & -5.509 & 6 & 0.002 \\
$50-59$ & -0.386 & 0.197 & -3.751 & 6 & 0.009 \\
$60-69$ & & & -4.374 & 4 & 0.012 \\
\hline
\end{tabular}

Note: $\$=$ mean group differences: control group - study group $(\mathrm{m} / \mathrm{s})$

$+=\mathrm{p}$ value after paired t-test

* $=$ significant $\mathrm{p}$ value $(\mathrm{p}<0.05)$

Predicted Maximum Oxygen Consumption

The mean value of $\mathrm{pVO} 2$ max in the study group was $17.61 \pm 2.54 \mathrm{ml} / \mathrm{kg} / \mathrm{min}(\mathrm{p}=0.118)$, and in the control group $24.06 \pm 3.62 \mathrm{ml} / \mathrm{kg} / \mathrm{min}(\mathrm{p}=$ 0.200). Distribution of the mean value of both group was normal.
The mean value pVO2max comparison between study and control group from the first and second tests was shown in Table 4. No significant difference was found between the first and second test results.

Table 4. Mean pVO2max from the First and Second Tests in Study and Control Groups

\begin{tabular}{|c|c|c|c|c|c|c|}
\hline \multirow[b]{2}{*}{$\begin{array}{c}\text { Age Clasification } \\
\text { (years) }\end{array}$} & \multicolumn{3}{|c|}{ Study $(N=19)$} & \multicolumn{3}{|c|}{ Control $(n=19)$} \\
\hline & $\begin{array}{c}\text { Mean } \\
\text { (ml/kg/ } \\
\text { menit) }\end{array}$ & SD & $\mathbf{p}^{+}$ & $\begin{array}{c}\text { Mean } \\
(\mathrm{ml} / \mathrm{kg} / \text { menit })\end{array}$ & SD & $\mathbf{p}^{+}$ \\
\hline \multicolumn{7}{|l|}{ Mean } \\
\hline Test 1 & 17.22 & 2.94 & & 23.68 & 3.79 & \\
\hline Test 2 & 17.99 & 2.36 & 0.055 & 24.44 & 3.74 & 0.133 \\
\hline \multicolumn{7}{|l|}{$40-49$} \\
\hline Test 1 & 18.58 & 2.09 & & 25.14 & 3.18 & \\
\hline Test 2 & 19.05 & 1.23 & 0.496 & 26.67 & 2.38 & 0.142 \\
\hline \multicolumn{7}{|l|}{$50-59$} \\
\hline Test 1 & 17.33 & 2.42 & & 24.26 & 3.94 & \\
\hline Test 2 & 18.21 & 2.81 & 0.212 & 25.05 & 3.44 & 0.392 \\
\hline \multicolumn{7}{|l|}{$60-69$} \\
\hline Test 1 & 15.19 & 3.88 & & 20.81 & 3.41 & \\
\hline Test 2 & 16.20 & 2.21 & 0.261 & 20.46 & 2.73 & 0.478 \\
\hline
\end{tabular}

Note: $\quad+{ }^{+}=\mathrm{p}$ value after paired t-test

There was a significant differences on the mean value of $\mathrm{pVO} 2 \mathrm{max}$ between the study and control groups $(p<0.0001$. The comparison of mean $\mathrm{pVO} 2 \mathrm{max}$ on both groups are shown in Picture 5. The result was also consistent within the age groups (Table 5). 


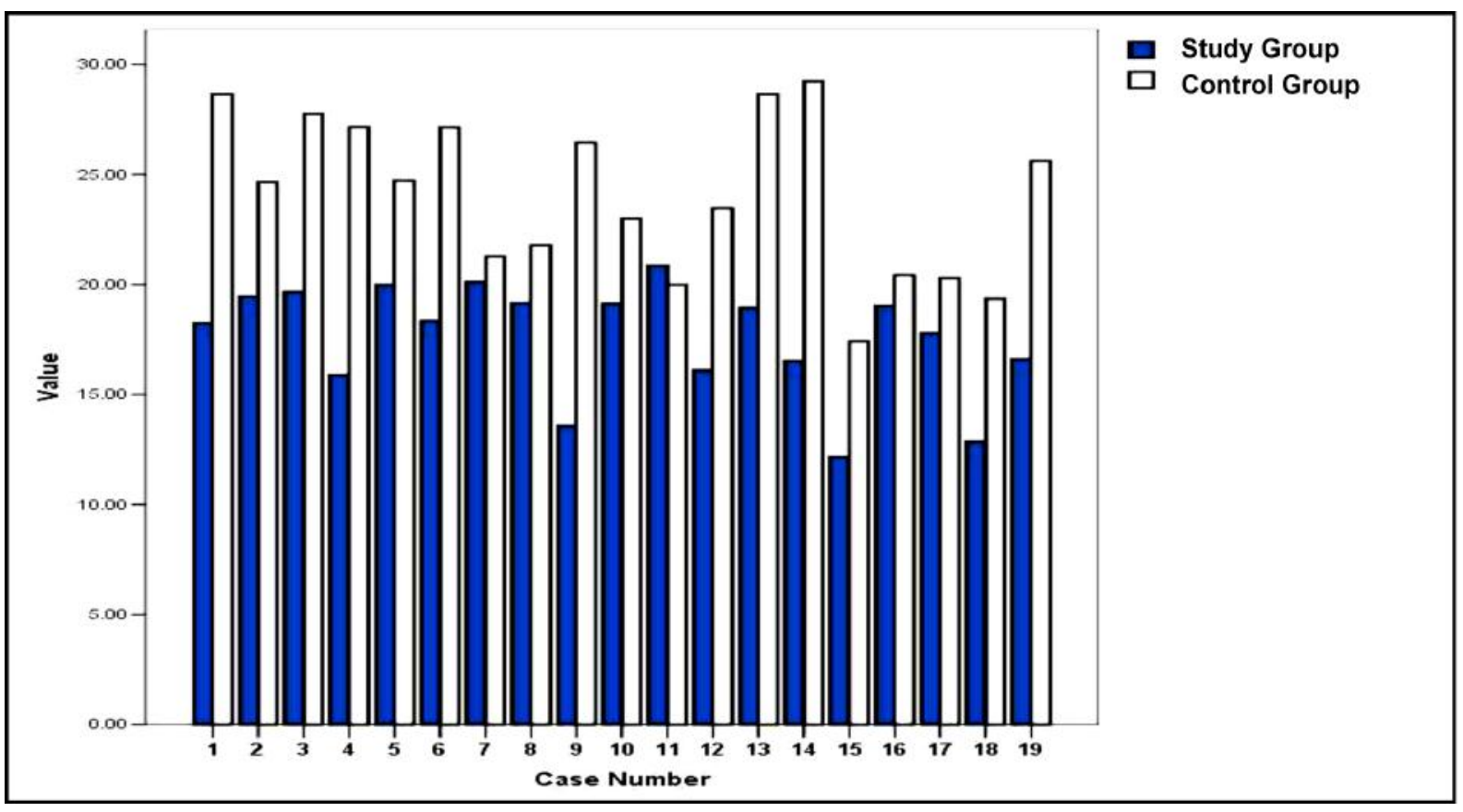

Picture 5. Comparison of Mean pVO2max between Study and Control Group

Table 3. Mean Walking Speed Comparison Between Study and Control Groups Based on the Age Classification

\begin{tabular}{cccccc}
\hline \multirow{2}{*}{$\begin{array}{c}\text { Age Classification } \\
\text { (Year) }\end{array}$} & \multicolumn{5}{c}{ Paired Differences } \\
\cline { 2 - 6 } & $\mathbf{\Delta}$ & SD & $\mathbf{t}$ & df & $\mathbf{p}^{*+}$ \\
\hline General & -6.452 & 4.059 & -6.928 & 18 & $<0.0001$ \\
$40-49$ & -7.094 & 3.579 & -5.243 & 6 & 0.002 \\
$50-59$ & -6.888 & 5.266 & -5.243 & 6 & 0.013 \\
$60-69$ & -4.942 & 3.070 & -3.599 & 4 & 0.023 \\
\hline
\end{tabular}

Note: $\S=$ mean group differences: control group - study group $(\mathrm{ml} / \mathrm{kg} / \mathrm{min})$

$+=\mathrm{p}$ value after paired $\mathrm{t}$-test

${ }^{*}=$ significant $\mathrm{p}$ value $(\mathrm{p}<0.05)$

Parameters Affecting pVO2max Calculations Other parameters affecting the pVO2max calculations include total elapsed time $\left(\mathrm{t}_{400 \mathrm{~m}}\right)$, longstride, and post test systolic blood pressure $\left(\mathrm{SBP}_{60}\right)$. The characteristics of these parameters are shown in Table 6. 
Table 6. Parameter Characteristics Affecting pVO2max Calculations on Study and Control Groups

\begin{tabular}{ccccccc}
\hline \multirow{2}{*}{ Parameter } & \multicolumn{3}{c}{ Study } & & \multicolumn{3}{c}{ Control (n= 19) } \\
\cline { 2 - 7 } & $\begin{array}{c}\text { Age Classifi- } \\
\text { cation }\end{array}$ & Mean & SD & Mean & SD & p+ \\
\hline t400m (seconds) & General & 317.03 & 45.56 & 233.66 & 30,44 & $<0.0001$ \\
& $40-49$ & 298.43 & 28.25 & 209.36 & 11,09 & 0.001 \\
& $50-59$ & 310.21 & 42.38 & 229.93 & 14,86 & 0.003 \\
& $60-69$ & 352.60 & 56.41 & 272.90 & 25,91 & 0.055 \\
Longstride & General & 30.32 & 2.91 & 24.45 & 1,69 & $<0.0001$ \\
(steps / 20 meters) & & & & & 0.003 \\
& $40-49$ & 29.29 & 2.27 & 24.00 & 1,63 & 0.005 \\
& $50-59$ & 29.64 & 3.16 & 24.14 & 1,18 & $<0.0001$ \\
SBP60 (mmHg) & $60-69$ & 32.70 & 2.36 & 25.50 & 2,21 & 0.807 \\
& General & 151.84 & 18.29 & 153.29 & 19,33 & 0.562 \\
& $40-49$ & 145.36 & 19.06 & 138.57 & 15,20 & 0.551 \\
& $50-59$ & 158.57 & 14.92 & 154.64 & 16,48 & 0.138 \\
\hline
\end{tabular}

Note: $\quad+=\mathrm{p}$ value after paired $\mathrm{t}$-test

* $=$ significant $\mathrm{p}$ value $(\mathrm{p}<0.05)$

Elapsed time (ET) in the study group was $317.03 \pm 45.56$ seconds. In the control group, ET was $233.66 \pm 30.44$ seconds. The ET was significantly different between the study and control groups $(\mathrm{P}<0.0001)$. Longstride was significantly different $(\mathrm{p}<0.0001)$ between the study $(30.32 \pm 2.91$ steps $/ 20 \mathrm{~m})$ and control groups (24.45 \pm 1.69 steps $/ 20 \mathrm{~m})$.

On SBP ${ }_{60}$ measurement, mean SBP on the study group was $151.84 \pm 18.29 \mathrm{mmHg}$, while the control group was $153.29 \pm 19.33 \mathrm{mmHg}$. Using a paired t-test analysis, no significant difference found between the two groups $(\mathrm{p}=0.807)$.

\section{DISCUSSION}

To the date this study was conducted, the 400 MWT has been exclusively used to evaluate walking performance in geriatric populations, and has not been used before in diabetic subjects. In this study, walking performance characterized by walking speed (WS) and predicted maximum oxygen consumption (pVO2max) were significantly lower in female diabetics subjects, compared to healthy individuals (Table 2 and Table 4). Walking performance is also affected by several factors including: fitness level, fatigue threshold, learning effect, and motivational effect., ${ }^{2,49-11}$

Reduced walking capacity in DM2 has been associated with a decrease in cardiopulmonary function. In a study by McGavock et al., female diabetics subjects showed significantly lower maximum oxygen consumtion $\left(\mathrm{VO}_{2 \max }\right)$, and predicted $\mathrm{VO}_{2 \max }$ compared with healthy subjects $(15.7 \pm 2.0 \mathrm{ml} /$ $\mathrm{kg} / \mathrm{min}$ and $21.9 \pm 3.0 \mathrm{ml} / \mathrm{kg} / \mathrm{min}$ ), despite the heart rate and systolic blood pressure differences between the two groups were not significant. The test demonstrated an increase in C-reactive protein level in diabetics subjects $(6.3 \pm 4.3 \mathrm{mg} / \mathrm{l}$ and $4.1 \pm 4.0 \mathrm{mg} / \mathrm{l})$, that ilustrates a decrease in aerobic capacity.

Lower limb dysfunction that leads to disability is a progressive state, related to a decrease in aerobic capacity. Volpato et al ${ }^{12}$ applied several exercise test including 4-meter walk test, five-chair stand test, and graded balance test to evaluate lower limb function in geriatric female with DM2. The study demonstrated significant decrease on lower limb function in diabetics subjects compared to the control group. This study also revealed walking disability in diabetics subjects marked by inability to walk 400 meters. The decrease in walking performance due to reduced aerobic 
capacity was also found in studies by Johnson et al, ${ }^{13}$ and Bjørgaas et al. ${ }^{14}$

In this study, subjects with DM2 showed a significantly slower walking speed compared to healthy individuals (Picture 4). Mean difference between the study and control groups was $0.45 \pm 0.26 \mathrm{~m} / \mathrm{s}(\mathrm{p}<0.0001)$. This findings was consistent when analyzed within the 3 age groups (Table 3). Lowest mean difference was found in the age $60-69$ years group $(\Delta=0.39 \pm 0.20 \mathrm{~m} / \mathrm{s}$, $\mathrm{p}=0.012$ ). Lowest walking speed in geriatric group (age $>60$ years) is consistent with several studies that demonstrated age influence to the functional walking ability that may also related to changes in gait pattern biomechanics. ${ }^{4,6,10}$

Several other factors may be responsible in reducing walking capacity in DM2 subjects, those include: vascular endothelium glycation and hemoglobin glycation, ${ }^{15-17}$ changes in musculoskeletal structure and function of the lower limbs, ${ }^{18,19}$ and decreased insulin vasodilatory effect and glucose uptake of the lower limb muscles. ${ }^{20,21}$ However these factors were not analyzed in our study.

The predicted $\mathrm{VO}_{2 \max }$ in the study group was also significantly lower compared to the control group $(17.61 \pm 2.54 \mathrm{ml} / \mathrm{kg} / \mathrm{min}$ and $24.06 \pm 3.62 \mathrm{ml} / \mathrm{kg} / \mathrm{min})$. Mean difference of pVO2max value between study and control group was $6.45 \pm 4.06$ ml.kg.min $(\mathrm{p}<0.0001)$. Previous study by Walker et al. found similar findings in female subjects with DM2 compared to normoglycemic female subjects prior to a 12week exercise program. In this study, the $\mathrm{VO}_{2 \max }$ in the study group was significantly lower to the control group $(18.7 \pm 3.2 \mathrm{ml} / \mathrm{kg} / \mathrm{min}$ and 20.7 $\pm 5.4 \mathrm{ml} / \mathrm{kg} / \mathrm{min}$ ), before the traininig period. ${ }^{22}$ Lower pVO2max findings were consistent within the 3 age groups (Table 5). Lowest mean difference was found on the geriatric groups $(\Delta=4.942 \pm 3.07 \mathrm{ml} / \mathrm{kg} / \mathrm{min} ; \mathrm{p}=0,023)$, with mean $\mathrm{pVO} 2 \mathrm{max}$ value of $20.64 \pm 3.07 \mathrm{ml} / \mathrm{kg} /$ $\mathrm{min}$. The result is consistent with previous study by Simonsick et al. ${ }^{7}$

There are two other parameters directly influence the pVO2max result, the elapsed time (ET) and longstride (LS). These parameters was calculated based on the equation developed by Simonsick et al. in the 400 MWT study. ${ }^{7}$

In previous study by Simonsick, if the
Åstrand estimation was applied to the 400 MWT, minimum or suboptimal oxygen consumption will reduced ET to 6 minutes 48 seconds -7 minutes 40 seconds to cover the $400-\mathrm{m}$ tract. The prediction $\mathrm{VO}_{2 \max }$ in this condition lies between $12-18 \mathrm{ml} / \mathrm{kg} / \mathrm{min}$. From this estimation, Simonsick stated that functional walking disability can be determined if ET is greater than 5 minutes 30 seconds to walk the 400 meters course. $^{7}$

Our study showed that the mean ET in the control group was 3 minutes $53 \pm 30.4$ seconds. In contrast to the study group, mean ET was 5 minutes $17 \pm 45.6$ seconds (Table 6 ). This finding was close to the threshold value in the Simonsick study. The longest ET on the study was found in the age 60-69 years group (5 minutes $52 \pm$ 56.4 seconds). The result demonstrated an indication of walking disability in this group. As a comparison, in earlier study by Simonsick, the ET in healthy geriatric subjects was 5 minutes 11 seconds. ${ }^{4}$

The influence of stride length in $\mathrm{VO}_{2 \max }$ measurement was introduced by Åstrand. In this study, stride length will affect energy economy in exercise test. According to Åstrand, greater stride lenght will result in greater speed, hence greater oxygen consumption. ${ }^{23}$ Simonsick et al. showed that stride length was an important adjustment factor in predicting $\mathrm{VO}_{2 \max }$. The term longstride (LS) in Simonsick's equation is a dichotomous variable to categorize subjects into those who had a long stride and those who had a short stride. Subjects with stride length $<24$ steps / 20 meters were categorized as longstride, with a score $=1$ and adjustment coefficient of 2.832. Whereas subjects with stride length $\geq 24$ steps / 20 meters were categorized as shortstride with a score $=0 .^{7}$

The stride length in our study was significantly differed between the study and control groups $(30.3 \pm 2.9$ steps $/ 20 \mathrm{~m}$ and 24.5 \pm 1.7 steps $/ 20 \mathrm{~m} ; \mathrm{p}<0.0001)$. However only 7 subjects in the control group had a stride length $<24$ steps $/ 20 \mathrm{~m}$ (mean value $=22.6$ steps $/ 20 \mathrm{~m}$ ), which put the majority of the subjects as a shortstrider. These findings may indicate that the dichotomous category in Simonsick study may not be appropriate in our study, and may become a bias in this study. It may be the race 
differences that influence the anthropometric factor in Asian population that give rise to the dyscrepancy. However this asumption will need further investigation.

\section{CONCLUSIONS}

Walking capacity was found significantly lower in female with DM2 compared to healthy female subjects, characterized by slower walking speed and lower predicted maximum oxygen consumption. There is a need to further investigate the use of the 400 MWT as an alternative exercise test to determine walking ability in various population and medical conditions. The validity of the test as an alternative measurement is also needs to be compared and standardized with the treadmill exercise test.

\section{REFERENCES}

1. McGavock JM, Mandic S, Muhll IV, Lewanczuk RZ, Quinney HA, Taylor DA, et al. Low cardiorespiratory fitness is associated with elevated $\mathrm{C}$-reactive protein levels in women with type 2 diabetes. Diabetes Care. 2004;27:320-5.

2. Verity LS. Diabetes mellitus and exercise. In: Kaminsky LA, Bonzheim KA, Garber $\mathrm{CE}$, et al. editors. ACSM's resource manual for guidelines for exercise testing and prescription, $5^{\text {th }}$ ed. Philadelphia: Lippincott Williams \& Wilkins 2006. p. 470-9.

3. Albright AL. Diabetes. In: American College of Sports Medicine: ACSM's exercise management for persons with chronic diseases and disabilities. New Zealand: Human Kinetics 1997. p. 94-100.

4. Simonsick EM, Montgomery PS, Newman A, Bauer DC, Harris T. Measuring fitness in healthy older adults: the health $\mathrm{ABC}$ long distance corridor walk. J Am Geriatr Soc. 2001;49:1544-8.

5. Gregg EW, Mangione CM, Cauley JA, et al. Diabetes and incidence of functional disability in older women. Diabetes Care.
2002;25:61-7.

6. Rolland YM, Cesari M, Miller ME, Penninx BW, Atkinson HH, Pahor M. Reliability of the 400-m usual-pace walk test as an assessment of mobility limitation in older adults. J Am Geriatr Soc. 2004;52:972-6.

7. Simonsick EM, Fan E, Fleg JL. Estimating cardiorespiratory fitness in well-functioning older adult: treadmill validation of long distance corridor walk. J Am Geriatr Soc. 2006;54:127-32.

8. Gregg EW, Brown A. Cognitive and physical disabilities and aging-related complications of diabetes. Clinical Diabetes. 2003;21:113-8.

9. Kingwell BA, Formosa M, Muhlmann $\mathrm{M}$, et al. Type 2 diabetic individuals have impaired leg blood flow responses to exercise: Role of endothelium-dependent vasodilation. Diabetes Care. 2003;26:899904

10. Chang M, Cohen-Mansfield J, Ferrucci L, Leveille S, Volpato S, de Rekeneire $\mathrm{N}$, et al. Incidence of loss of ability to walk 400 meters in a functionally limited older population. J Am Geriatr Soc. 2004;52:2094-8.

11. Solway S, Brooks D, Lacasse Y, Thomas S. A qualitative systematic overview of the measurement properties of functional walk test used in the cardiorespiratory domain. Chest. 2001;119:256-70.

12. Volpato S, Ferrucci L, Blaum C, Ostir G, Cappola A, Fried LP, et al. Progression of lower-extremity disability in older women with diabetes. Diabetes Care 2002;26:705.

13. Johnson ST, Tudor-Locke C, McCargar LJ, Bell RJ. Measuring habitual walking speed of people with type 2 diabetes: Are the meeting recommendations? Diabetes Care. 2005;28:1503-4.

14. Bjørgaas M, Vik JT, Sæterhaug A, Langlo L, Sakshaug T, Mohus RM, et al. Relationship between pedometerregistered activity, aerobic capacity and self-reported activity and fitness in patients with type 2 diabetes. Diabetes, Obesity and Metabolism. 2005;7:737-44.

15. Qin X, Goldfine A, Krumrei N, Grubissich 
L, Ascota J, Chorev M, et al. Glycation inactivation of the complement regulatory protein CD59: A possible role in the pathogenesis of the vascular complications of human diabetes. Diabetes. 2004;53:2653-61.

16. Donnelly R, Davis KR. Type 2 diabetes and atherosclerosis. Diabetes, Obesity and Metabolism. 2000;2 (Suppl. 1):S21-S30.

17. Varughese GI, Tomson J, Lip GYH. Type 2 diabetes mellitus: a cardiovascular perspective. Int $\mathrm{J}$ Clin Pract. 2005;59(7):798-816.

18. Andersen H, Gjerstad MD, Jakobsen J. Atrophy of foot muscles. Diabetes Care. 2004;27:2382-85.

19. Andersen H, Nielsen S, Mogensen CE, Jakobsen J. Muscle strength in type 2 diabetes. Diabetes. 2004;53:1543-8.
20. Gudbjörnsdøttir S, Sjöstrand M, Strindberg L, Lönnroth P. Decreased muscle capillary permeability surface area in type 2 diabetic subjects. J Clin Endocrinol Metab. 2005;90:1078-82.

21. Vincent MA, Dawson D, Clark ADH, et al. Skeletal muscle microvascular recruitment by physiological hyperinsulinemia precedes increases in total blood flow. Diabetes. 2002;51:42-48.

22. Walker KZ, Piers LS, Putt RS, Jones JA, O'Dea K. Effects of regular walking on cardiovascular risk factors and body composition in normoglycemic women and women with type 2 diabetes. Diabetes Care. 1999;22:555-61.

23. Åstrand PO, Rodahl K. Textbook of work physiology. $3^{\text {rd }}$ ed. New York: McGrawHill; 1986. 